\title{
Microstructure and Thermal Analysis of As-Cast Ag-Bi-Ni alloys
}

\author{
PRZEMYSLAW FIMA, ${ }^{1,3}$ GRZEGORZ GARZEL, ${ }^{1}$ and KATARZYNA BERENT ${ }^{2}$ \\ 1.-Institute of Metallurgy and Materials Science, Polish Academy of Sciences, 30-059 Krakow, \\ Poland. 2.-Academic Centre for Materials and Nanotechnology, AGH University of Science and \\ Technology, 30-059 Krakow, Poland. 3.-e-mail: p.fima@imim.pl
}

The calculated liquidus projection of the Ag-Bi-Ni ternary system has been experimentally examined. Alloys were prepared by induction melting, and their microstructure studied by scanning electron microscopy coupled with energy dispersive x-ray spectroscopy. Of the primary solidification phases, (Ni) solidifies over the largest concentration range, although it was found to be narrower than calculated. The range in which $\mathrm{Bi}_{3} \mathrm{Ni}$ is the primary solidification phase was found to be broader than calculated. Also, the liquid miscibility gap is broader than predicted from assessed thermodynamic parameters. Differential thermal analysis was used to study temperatures of phase transitions of as-cast alloys, and recorded temperatures of melting of $\mathrm{Bi}_{3} \mathrm{Ni}$ and $\mathrm{BiNi}$ phases in ternary alloys agree well with those calculated.

Key words: Ag-Bi-Ni system, microstructure, primary solidification, thermal analysis

\section{INTRODUCTION}

Among alloys considered as $\mathrm{Pb}$-free replacement for solders used at high temperatures, Bi-2.5Ag and $\mathrm{Bi}-11 \mathrm{Ag}$ (wt.\%) alloys are subjects of interest to investigators. $^{1,2}$ Also, a number of Ag-Bi-X systems have been studied as possible candidate ${ }^{3}$ to replace solders such as $\mathrm{Sn}-90 \mathrm{~Pb}$ (wt.\%). The systems studied, both thermodynamically and with respect to phase equilibria, have included $\mathrm{Ag}-\mathrm{Bi}-\mathrm{Cu}, \mathrm{Ag}-\mathrm{Bi}-\mathrm{Sn}, \mathrm{Ag}-\mathrm{Bi}-$ $\mathrm{Zn},{ }^{4-6}$ and $\mathrm{Ag}-\mathrm{Bi}-\mathrm{Ni}^{7}$ The phase diagram of the Ag$\mathrm{Bi}-\mathrm{Ni}$ system was thermodynamically assessed by Gao et al. $^{7}$ They found that there are no ternary intermetallics in this system, and that the solubility of $\mathrm{Ag}$ in the two binary intermetallics, i.e. BiNi and $\mathrm{Bi}_{3} \mathrm{Ni}$, is negligible. Because of a lack of experimental data regarding liquidus surface and thermodynamics of liquid phase, they based their assessment only on experimental phase equilibria in four isothermal sections in the Ag-Bi-Ni system and thermodynamic assessed data of limiting binary systems. ${ }^{8-10}$

The aim of this work is to experimentally verify the liquidus projection of the Ag-Bi-Ni system. This aim is achieved by identifying primary solidification

(Received May 2, 2015; accepted November 4, 2015; published online December 1, 2015) phases for selected alloy compositions. The primary solidification phase is the solid phase formed first during the solidification process. ${ }^{11}$

\section{EXPERIMENTAL}

In total, 15 alloy compositions, lying along three sections of constant $\mathrm{Ag}$ to Bi molar ratio equal to 4:1, $1: 1,1: 4$, and one section of constant $\mathrm{Ag}$ to $\mathrm{Ni}$ molar ratio equal to $4: 1$ (see Fig. 1), were synthesized by melting accurately weighed amounts of pure constituents: Ag (99.99 wt.\%), Bi (99.999 wt.\%), and Ni (99.99 wt.\%). Alloys were prepared by induction melting ${ }^{12}$ in cylindrical quartz crucibles and allowed to cool in the same crucibles. In order to avoid oxidation, the apparatus was flushed with high-purity Ar (99.999 vol.\%) before melting, and gas flow was maintained during melting and cooling. It took up to $40 \mathrm{~min}$ from switching off the induction current before the gas flow was switched off and the sample removed from the crucible. Induction melting was chosen because it allows for rapid heating and guarantees intensive mixing of liquids, thus limiting the time an alloy is kept in the liquid state. This is important in the present case, because, at the melting point of $\mathrm{Ni}$, the vapor pressure of $\mathrm{Bi}$ is several orders of magnitude higher than that of $\mathrm{Ni}$, which could lead to a mass loss in 
alloys. The masses of prepared alloys were checked to an accuracy of $0.0001 \mathrm{~g}$ and the mass loss did not exceed $1 \%$. Next, the as-cast samples were cut along the axis of symmetry. One-half was ground and polished and, after being ultrasonically cleaned in acetone and dried in air, subjected to microstructure characterization, while samples from the second half were cut out for DTA analysis.

The DTA investigations were carried out using a Netzsch 404 F1 Pegasus. Before the DTA experiments, the sensitivity and temperature calibrations were performed by measuring the onsets of thermal effects accompanying the melting of pure elements (In, Sn, Bi, Zn, Al and Ag) using the same working conditions. The accuracy of the DTA measurement was determined to be $\pm 1 \mathrm{~K}$. Samples of $70-110 \mathrm{mg}$ were ultrasonically cleaned in acetone and placed in quartz ampoules of $4 \mathrm{~mm}$ internal and $6 \mathrm{~mm}$ external diameters. Each ampoule was evacuated and flushed with Ar protective gas at least three times before it was sealed under Ar pressure lowered to 1 mbar. Ampoules were placed in an alumina crucible with a hollow bottom so that the thermocouple was directly in contact with the bottom of the ampoule. As a reference, an ampoule of the same dimensions filled with an inert gas was used. The samples were heated at a relatively low rate of $10 \mathrm{~K} /$ min and DTA curves were recorded. It is known that, in the case of alloys containing a component which is more volatile than the others ( $\mathrm{Bi}$ in the present case), a mass loss might occur which is equivalent to a change of sample composition. ${ }^{13}$ This can be observed on heating curves (shifting peaks) if the heating runs are repeated. In order to avoid this phenomenon, we limited the number of

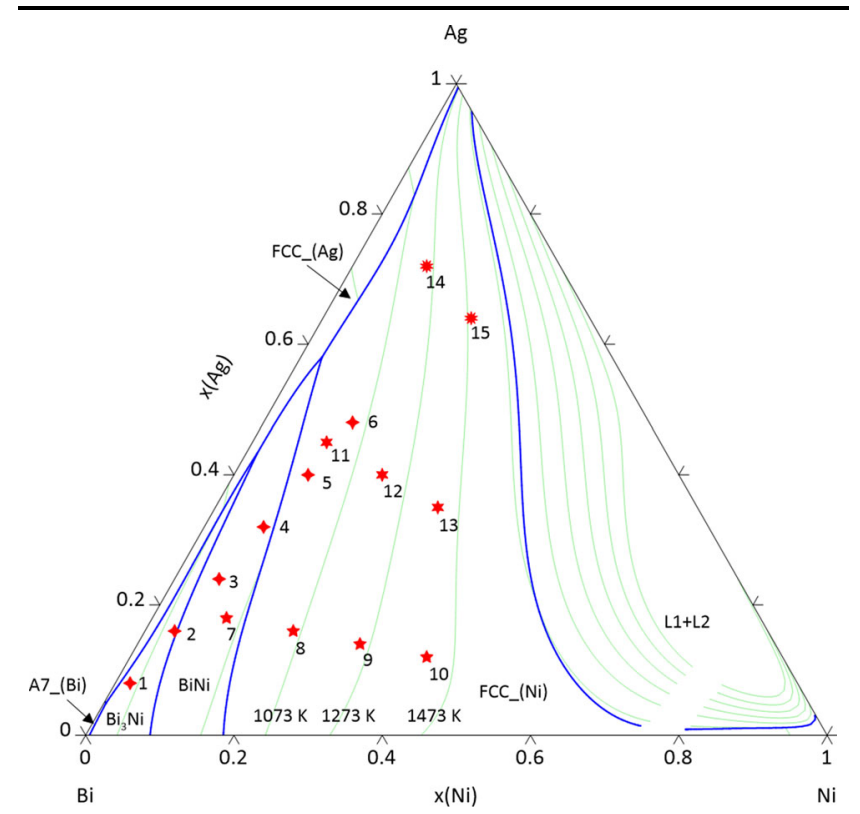

Fig. 1. Alloy compositions studied, imposed on a liquidus projection of the $\mathrm{Ag}$-Bi-Ni system calculated from thermodynamic assessment. ${ }^{7}$ heating runs to two as well as limited the maximum temperature to $1173 \mathrm{~K}$.

A SEM-EDS study was performed with Quanta 3D FEG with an Apollo 40 SSD detector for x-ray microanalysis, at $20 \mathrm{kV}$. Microstructural observation was conducted by backscattered electron (BSE) imaging, providing information about the distribution of different elements in the samples. The quantitative EDS analysis was performed on several regions of cross-sectioned samples. To minimize the effect of interaction volume, the beam energy was two times higher than the critical ionization energy to excite the characteristic x-ray from the elements of interest. Additionally, three analyses were collected from each phase and the average value was given as a result of the measurements. The measurements have a relative accuracy of about $\pm 1 \%$.

The liquidus projection and isopleths in the Ag$\mathrm{Bi}-\mathrm{Ni}$ system were calculated from thermodynamic assessed data provided in Ref. 7 with the use of the Pandat 2.1 software package by CompuTherm.

\section{RESULTS AND DISCUSSION}

Figure 1 illustrates the liquidus projection of the Ag-Bi-Ni system calculated based on the thermodynamic assessment. ${ }^{7}$ The calculated liquid miscibility gap extends from the Ag-Ni side up to approximately 30 at.\% Bi. For the remaining part of the Ag$\mathrm{Bi}-\mathrm{Ni}$ system, depending on composition, the primary solidification phases are: $(\mathrm{Ni}),(\mathrm{Ag}), \mathrm{BiNi}$, $\mathrm{Bi}_{3} \mathrm{Ni}$, and $(\mathrm{Bi})$. The numbered points in Fig. 1 represent the alloys investigated in this study, which are listed in Table I together with their nominal composition. The EDS analysis was performed on cross-sections of as-cast alloys to check if it matches their nominal composition. The results, together with the relative error of analysis, are reported in Table I. One can see that, for alloys \#3, $\# 9$, \#10, \#12, and \#14, the average composition determined with EDS diverges from the nominal more than for the others. Aside from EDS method limitations, this can be partly explained by the randomness of distribution of the phases in each sample's volume and the fact that only one crosssection was investigated. As discussed later, we observed that alloy \#15 segregates into two immiscible liquids and because of this it was not possible to determine its average composition.

Figure 2 presents DTA curves, with 1-3 distinct peaks, recorded on heating for the 15 samples indicated in Fig. 1. For all the investigated samples, a peak was recorded with onset at $\sim 535 \mathrm{~K}$, which is close to the melting of the eutectic in the Ag-Bi binary system. ${ }^{8}$ Also, for all alloy samples except for \#1-\#3, a peak was recorded with onset at $\sim 690 \mathrm{~K}$. This temperature is roughly $45 \mathrm{~K}$ lower than the melting temperature of $\mathrm{Bi}_{3} \mathrm{Ni}^{9}$. For alloys \#5, \#6, \#8-\#15, a third peak was recorded with onset between $813 \mathrm{~K}$ (alloy \#15) and $865 \mathrm{~K}$ (alloy \#8). 
Table I. Compositions and primary solidification phases of the examined alloys

\begin{tabular}{|c|c|c|c|c|c|c|c|}
\hline \multirow[b]{2}{*}{ Alloy \# } & \multicolumn{3}{|c|}{$\begin{array}{l}\text { Nominal compo- } \\
\text { sition (at.\%) }\end{array}$} & \multicolumn{3}{|c|}{ Average composition from EDS (at.\%) } & \multirow[b]{2}{*}{ Primary solidification phase } \\
\hline & $\mathbf{A g}$ & $\mathbf{B i}$ & $\mathbf{N i}$ & Ag & $\mathbf{B i}$ & $\mathbf{N i}$ & \\
\hline 1 & 8 & 90 & 2 & $8.8 \pm 0.4$ & $88.3 \pm 1.8$ & $2.9 \pm 0.3$ & $\mathrm{Bi} 3 \mathrm{Ni}$ \\
\hline 2 & 16 & 80 & 4 & $18.1 \pm 0.7$ & $77.3 \pm 1.5$ & $4.6 \pm 0.5$ & $\mathrm{Bi} 3 \mathrm{Ni}$ \\
\hline 3 & 24 & 70 & 6 & $29.6 \pm 0.6$ & $64.0 \pm 1.3$ & $6.4 \pm 0.3$ & $\mathrm{Bi} 3 \mathrm{Ni}$ \\
\hline 4 & 32 & 60 & 8 & $34.1 \pm 0.7$ & $58.8 \pm 1.2$ & $7.1 \pm 0.3$ & $(\mathrm{Ni})$ \\
\hline 5 & 40 & 50 & 10 & $42.0 \pm 0.8$ & $49.6 \pm 1.0$ & $8.4 \pm 0.3$ & $(\mathrm{Ni})$ \\
\hline 6 & 48 & 40 & 12 & $47.8 \pm 1.0$ & $41.8 \pm 0.8$ & $10.4 \pm 0.4$ & $(\mathrm{Ni})$ \\
\hline 7 & 18 & 72 & 10 & $20.4 \pm 0.4$ & $70.0 \pm 1.4$ & $9.6 \pm 0.4$ & $\mathrm{BiNi}$ \\
\hline 8 & 16 & 64 & 20 & $16.6 \pm 0.7$ & $66.0 \pm 1.3$ & $17.4 \pm 0.7$ & $(\mathrm{Ni})$ \\
\hline 9 & 14 & 56 & 30 & $16.7 \pm 0.7$ & $59.7 \pm 1.2$ & $23.6 \pm 0.5$ & $(\mathrm{Ni})$ \\
\hline 10 & 12 & 48 & 40 & $14.0 \pm 0.6$ & $52.7 \pm 1.1$ & $33.3 \pm 0.7$ & $(\mathrm{Ni})$ \\
\hline 11 & 45 & 45 & 10 & $44.7 \pm 0.9$ & $46.1 \pm 0.9$ & $9.2 \pm 0.4$ & $(\mathrm{Ni})$ \\
\hline 12 & 40 & 40 & 20 & $40.4 \pm 0.8$ & $42.9 \pm 0.9$ & $16.7 \pm 0.7$ & $(\mathrm{Ni})$ \\
\hline 13 & 35 & 35 & 30 & $36.1 \pm 0.7$ & $35.5 \pm 0.7$ & $28.4 \pm 0.6$ & $\mathrm{~L} 1+\mathrm{L} 2$ \\
\hline 14 & 72 & 18 & 10 & $65.9 \pm 1.3$ & $20.8 \pm 0.4$ & $13.3 \pm 0.5$ & $(\mathrm{Ni})$ \\
\hline 15 & 64 & 16 & 20 & - & - & - & $\mathrm{L} 1+\mathrm{L} 2$ \\
\hline
\end{tabular}

(a)

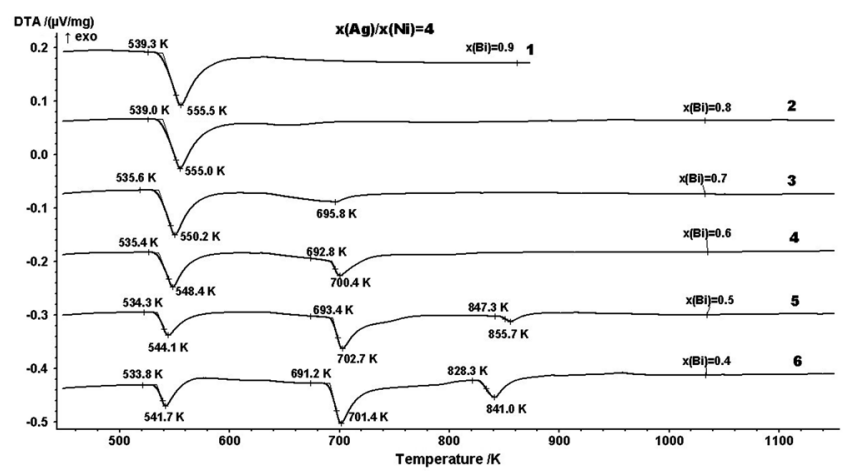

(c)

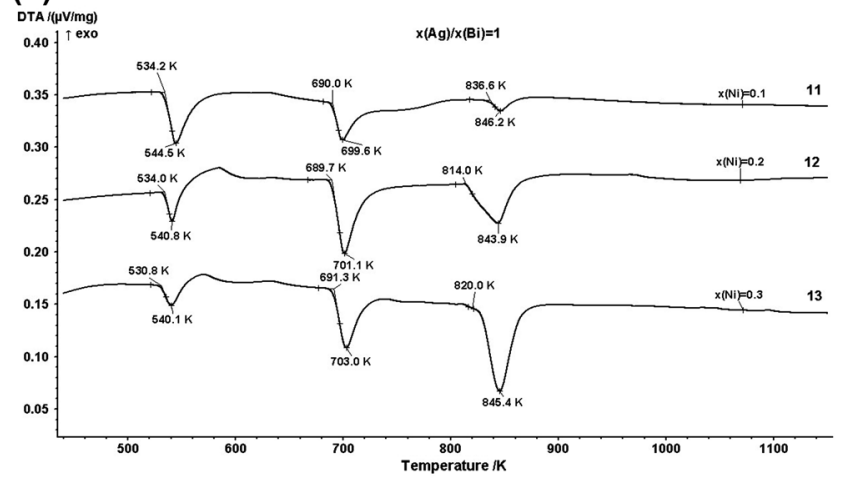

(b)

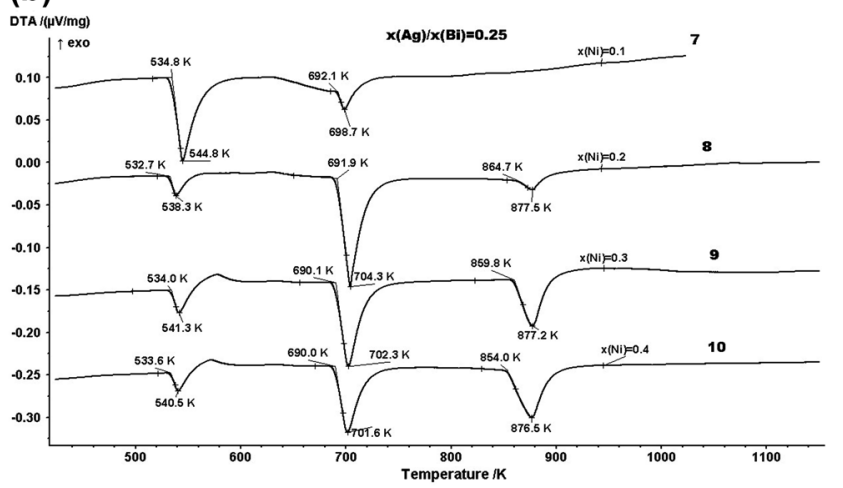

(d)

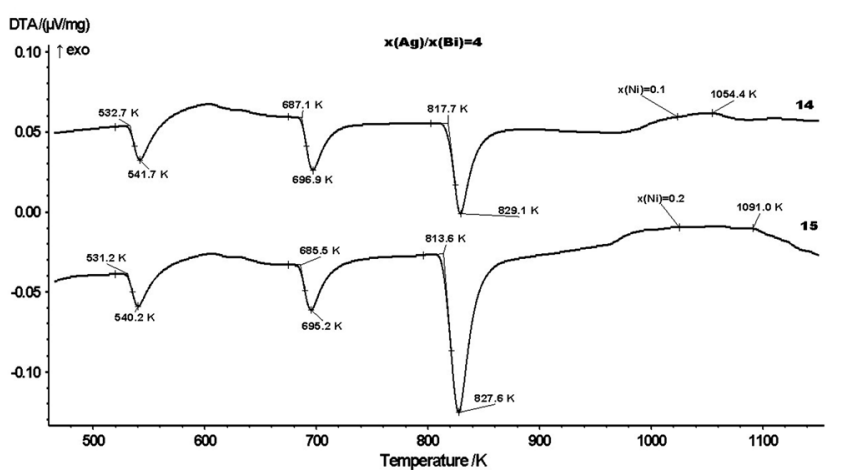

Fig. 2. DTA curves recorded on heating for Ag-Bi-Ni alloys: (a) $\times(\mathrm{Ag}) / \times(\mathrm{Ni})=4: 1 ;$ (b) $\times(\mathrm{Ag}) / \times(\mathrm{Bi})=1: 4 ;(\mathrm{c}) \times(\mathrm{Ag}) / \times(\mathrm{Bi})=1: 1 ;(\mathrm{d}) \times(\mathrm{Ag}) /$ $\times(\mathrm{Bi})=4: 1$. Consecutive numbers correspond to alloy number in Fig. 1 .

These temperatures are $50-100 \mathrm{~K}$ lower than the melting temperature of the BiNi phase in the $\mathrm{Bi}-\mathrm{Ni}$ binary. ${ }^{9}$ Peaks which could have been associated with liquidus transition were not recorded, either because for some alloys the liquidus is higher than the maximum temperature of the present DTA test, or because the amount of solid phase taking part in liquidus transition was too small to produce a detectable heat effect.

In Fig. 3, isopleths calculated using thermodynamic parameters ${ }^{7}$ are shown for various molar ratios of $\mathrm{Ag}$ to $\mathrm{Ni}$ and $\mathrm{Ag}$ to $\mathrm{Bi}$. The points in Fig. 3 

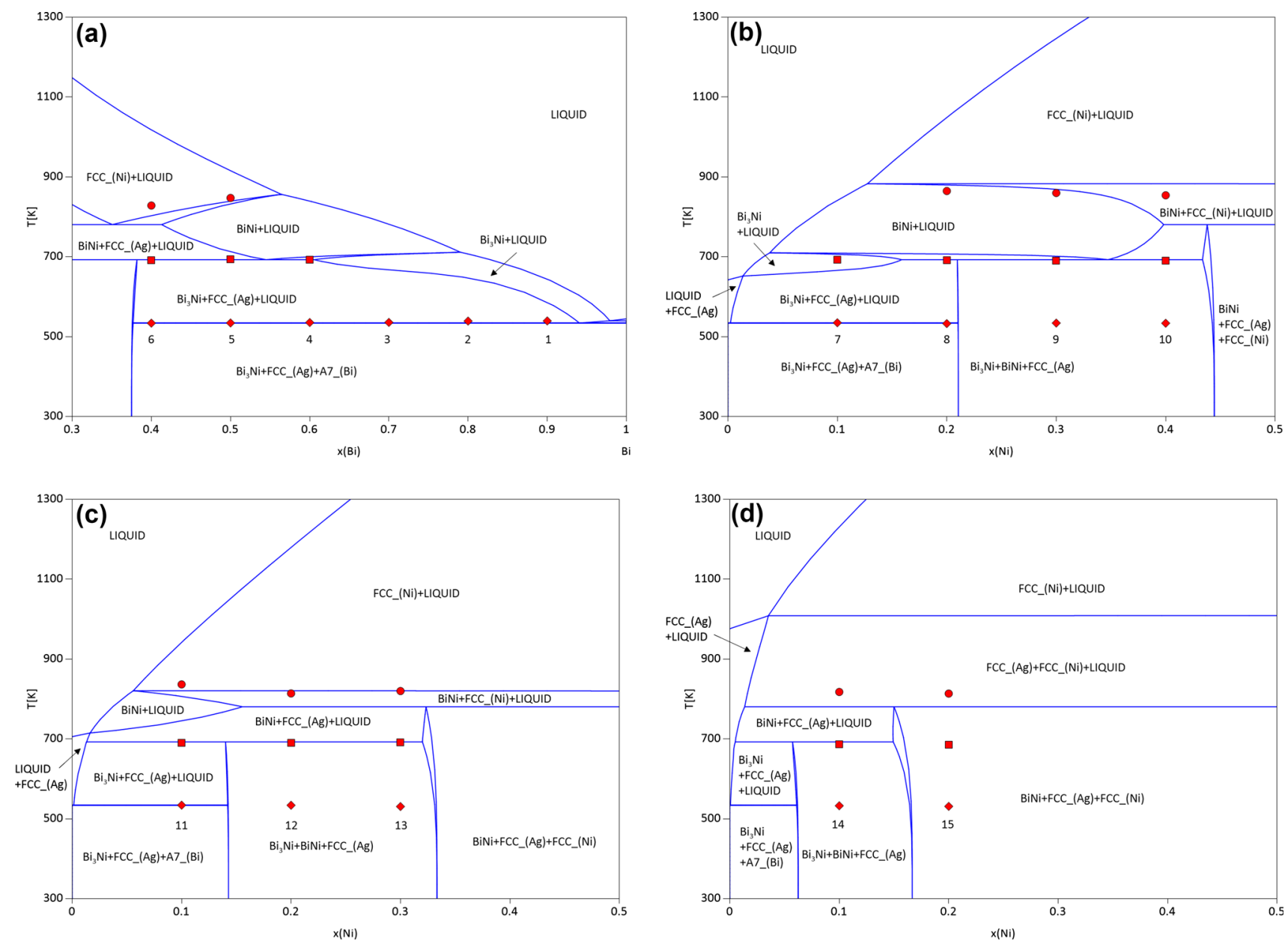

Fig. 3. Isopleths calculated in the Ag-Bi-Ni ternary system using thermodynamically assessed parameters ${ }^{7}$ for: $(\mathrm{a}) \times(\mathrm{Ag}) / \times(\mathrm{Ni})=4: 1 ;(\mathrm{b}) \times(\mathrm{Ag}) /$ $\times(\mathrm{Bi})=4: 1 ;(\mathrm{c}) \times(\mathrm{Ag}) / \times(\mathrm{Bi})=1: 1 ;(\mathrm{d}) \times(\mathrm{Ag}) / \times(\mathrm{Bi})=4: 1$. Symbols correspond to onsets of transitions indicated by peaks in Fig. 2 . (diamond onset of peak 1 ; square onset of peak 2 ; circle onset of peak 3 ).

indicate onset temperatures of the peaks shown in Fig. 2. For the molar Ag to Ni ratio equal to 4:1 (Fig. 3a), the overall agreement between the DTA results and calculations is rather good. The transition at $\sim 535 \mathrm{~K}$, which corresponds to ternary eutectic liquid $->\mathrm{Bi}_{3} \mathrm{Ni}+(\mathrm{Ag})+(\mathrm{Bi})^{7}$ is well reproduced by the experimental data. Also, the transition occurring at $\sim 690 \mathrm{~K}$ is well reproduced for alloys containing a $0.4-0.6 \mathrm{~mol}$ fraction of $\mathrm{Bi}$ (alloys \#4, \#5, \#6). For alloys \#5 and \#6, the third peak corresponds well with the melting of the BiNi phase. For sections of the molar $\mathrm{Ag}$ to $\mathrm{Bi}$ ratio equal to $1: 4,1: 1,4: 1$ (Fig. 3b-d), the agreement between the DTA results and calculations is not as good regarding the transitions at $\sim 535 \mathrm{~K}$ occurring for samples of reduced Bi content (\#9, \#10, \#12, \#13, \#14). For the same alloys, regardless of differences between the calculations and experimentally determined onset, transitions corresponding to the melting of $\mathrm{Bi}_{3} \mathrm{Ni}$ and $\mathrm{BiNi}$ phases are well reproduced. For alloy \#15, peaks with onset at $\sim 535 \mathrm{~K}$ and $\sim 690 \mathrm{~K}$ were recorded, which should not be present according to the calculations. The discrepancy between the calculations and experimentally determined transition temperatures is understandable considering the samples studied were not annealed before the DTA tests, and therefore their microstructure and phase composition are different from phase equilibrium. Likely, in addition to $\mathrm{Bi}_{3} \mathrm{Ni}+\mathrm{BiNi}+(\mathrm{Ag})$ or, depending on composition, $\mathrm{BiNi}+(\mathrm{Ag})+(\mathrm{Ni})$, there is a substantial amount of additional low-melting Bi-rich phase. If the samples were equilibrated at elevated temperatures for a sufficient time, this Birich phase would be consumed by growing $\mathrm{Bi}_{3} \mathrm{Ni}$ and BiNi phases.

Figure 4a illustrates the microstructure of alloy \#1, with large dark grey precipitates and smaller light grey precipitates in the lighter matrix, which is composed of dotted eutectic-like areas and light areas. According to the EDS analysis in Table II, these dark grey precipitates are (Ag) with 5.6 at.\% of dissolved $\mathrm{Bi}$, which is about the maximum solubility of $\mathrm{Bi}$ in solid (Ag) according to the $\mathrm{Ag}-\mathrm{Bi}$ phase diagram. ${ }^{8}$ The smaller light grey precipitates were deduced to be $\mathrm{Bi}_{3} \mathrm{Ni}$, and the light areas in the matrix are mostly $(\mathrm{Bi})$ phase. Close inspection of the 


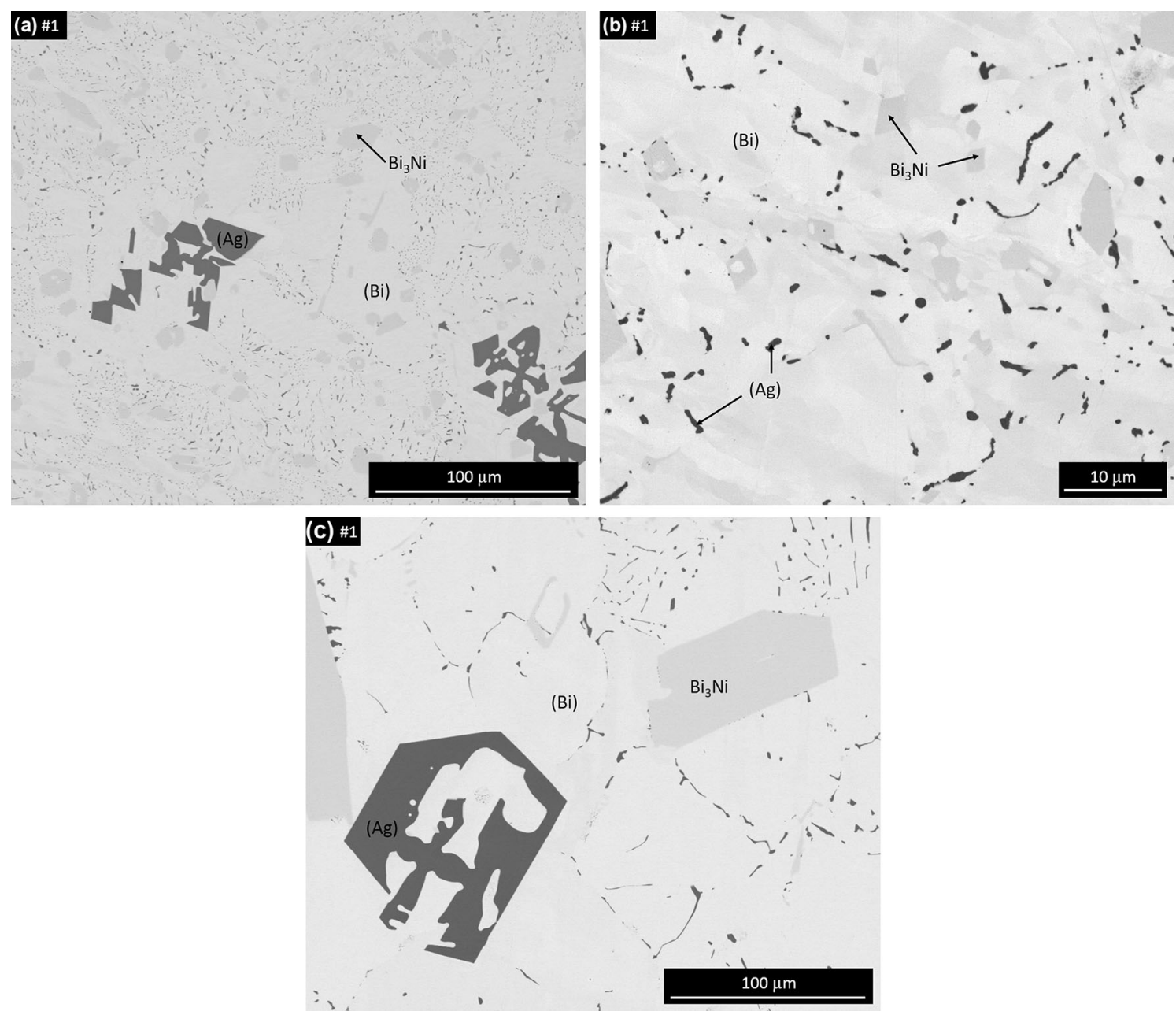

Fig. 4. SEM-BSE micrographs of alloy \#1 Ag-90Bi-2Ni: (a) and (b) as-solidified at low and high magnification, respectively, (c) after DTA.

eutectic-like areas (Fig. 4b) revealed very small precipitates of $(\mathrm{Ag})$ and larger precipitates of $\mathrm{Bi}_{3} \mathrm{Ni}$ in the $(\mathrm{Bi})$ matrix, meaning that this is actually a ternary eutectic. ${ }^{7}$ Based on this, $\mathrm{Bi}_{3} \mathrm{Ni}$ was assumed to be the primary solidification phase for alloy \#1. The variation of contrast in the $(\mathrm{Bi})$ matrix in Fig. $4 \mathrm{~b}$ is a result of orientation contrast due to the channeling effect, visible at the high magnification at lower accelerating voltage $(10 \mathrm{kV})$ applied to obtain this particular micrograph. Due to relatively fast cooling, fine microstructure of as-cast alloy \#1 was obtained. The microstructure of the same alloy after DTA test, with cooling rate of $10 \mathrm{~K} / \mathrm{min}$, is coarse and the ternary eutectic $\mathrm{Bi}_{3} \mathrm{Ni}+(\mathrm{Ag})+(\mathrm{Bi})$ areas are clearly visible (Fig. $4 \mathrm{c}$ ). In the case of alloy \#2, of the same Ag to Ni molar ratio equal to 4:1, the large light grey precipitates were found to have a composition close to the $\mathrm{Bi}_{3} \mathrm{Ni}$ phase, and were deduced to be the primary solidification phase. The microstructure of the as-cast alloy \#3 (Fig. 5a) is similar to that of alloy \#2, although the number of precipitates of the dark grey phase and the size of precipitates of the light grey phase increased. As indicated in Table II, the dark grey phase is $(\mathrm{Ag})$ and the light grey phase was confirmed to be $\mathrm{Bi}_{3} \mathrm{Ni}$ by x-ray diffraction (Fig. 6). There are distinct peaks from $(\mathrm{Bi})$ and $\mathrm{Bi}_{3} \mathrm{Ni}$, both overlapping with peaks from $(\mathrm{Ag})$. Based on this evidence, the $\mathrm{Bi}_{3} \mathrm{Ni}$ was found to be the primary solidification phase for alloy \#3, which contradicts the calculated liquidus projection. According to the calculated liquidus projection (Fig. 1), the primary solidification phase for alloy \#4 should be BiNi. Close inspection of the microstructure of sample \#4 (Fig. 5b), supported by EDS analysis results, revealed a fairly low number of small areas identified as $\mathrm{BiNi}$, embedded in larger areas identified as $\mathrm{Bi}_{3} \mathrm{Ni}$. These and precipitates of $(\mathrm{Ag})$ are distributed in the $(\mathrm{Bi})$ matrix. In addition, very small, single precipitates identified as $(\mathrm{Ni})$ were found (marked with dotted circles in Fig. 5b), suggesting that $(\mathrm{Ni})$ may in fact be the primary solidification phase for alloy \#4. The precipitates of the (Ni) phase represent a tiny fraction of the investigated microstructure and the amount is too small to produce a detectable heat effect (Fig. 2a). Single (Ni) precipitates, only larger, are found in alloy \#4 after DTA, which confirms that it is the primary solidification phase. For alloys \#5 and \#6 (Fig. 5c), the 
Table II. EDS analysis results of selected Ag-Bi-Ni samples, with phases identified

\begin{tabular}{|c|c|c|c|c|}
\hline \multirow[b]{2}{*}{ Alloy \# } & \multicolumn{3}{|c|}{ Composition (at.\%) } & \multirow[b]{2}{*}{ Phase } \\
\hline & Ag & $\mathbf{B i}$ & $\mathbf{N i}$ & \\
\hline \multirow[t]{3}{*}{1} & - & $78.0 \pm 1.6$ & $22.0 \pm 0.9$ & $\mathrm{Bi} 3 \mathrm{Ni}$ \\
\hline & $94.4 \pm 1.9$ & $5.6 \pm 0.2$ & - & $(\mathrm{Ag})$ \\
\hline & - & $100.0 \pm 2.0$ & - & $(\mathrm{Bi})$ \\
\hline \multirow[t]{3}{*}{3} & - & $67.6 \pm 1.4$ & $32.4 \pm 0.6$ & $\mathrm{Bi} 3 \mathrm{Ni}$ \\
\hline & - & $100.0 \pm 2.0$ & - & (Bi) \\
\hline & $99.2 \pm 2.0$ & $0.8 \pm 0.4$ & - & $(\mathrm{Ag})$ \\
\hline \multirow[t]{5}{*}{6} & - & - & $100.0 \pm 2.0$ & $(\mathrm{Ni})$ \\
\hline & $0.5 \pm 0.2$ & $47.5 \pm 1.0$ & $52.0 \pm 1.0$ & $\mathrm{BiNi}$ \\
\hline & - & $77.6 \pm 1.6$ & $22.4 \pm 0.9$ & $\mathrm{Bi} 3 \mathrm{Ni}$ \\
\hline & $93.0 \pm 1.9$ & $7.0 \pm 0.3$ & - & $(\mathrm{Ag})$ \\
\hline & - & $98.1 \pm 2.0$ & $1.9 \pm 0.4$ & $(\mathrm{Bi})$ \\
\hline \multirow[t]{5}{*}{8} & - & - & $100.0 \pm 2.0$ & $(\mathrm{Ni})$ \\
\hline & - & $58.3 \pm 1.2$ & $41.7 \pm 0.8$ & $\mathrm{BiNi}$ \\
\hline & - & $77.7 \pm 1.6$ & $22.3 \pm 0.5$ & $\mathrm{Bi} 3 \mathrm{Ni}$ \\
\hline & $100.0 \pm 2.0$ & - & - & $(\mathrm{Ag})$ \\
\hline & - & $97.8 \pm 2.0$ & $2.2 \pm 0.4$ & $(\mathrm{Bi})$ \\
\hline \multirow[t]{2}{*}{13} & $35.2 \pm 0.7$ & $34.6 \pm 0.7$ & $30.2 \pm 0.6$ & $\mathrm{~L} 1$ \\
\hline & $1.4 \pm 0.3$ & $1.2 \pm 0.2$ & $97.4 \pm 2.0$ & L2 \\
\hline \multirow[t]{2}{*}{15} & $74.0 \pm 1.5$ & $12.0 \pm 0.5$ & $14.0 \pm 0.6$ & L1 \\
\hline & $1.8 \pm 0.4$ & $0.9 \pm 0.4$ & $97.3 \pm 1.9$ & L2 \\
\hline
\end{tabular}

(Ni) was found to be the primary solidification phase, with the number and size of $(\mathrm{Ni})$ precipitates increasing with decreasing Bi concentration. A lower cooling rate in the DTA test, as shown in Fig. 5d for alloy \#6, leads to coarsening of the microstructure. After DTA (Fig. 5d), precipitates of (Ni) are significantly larger compared to the as-cast alloy (Fig. 5c), and it is also more clear that the light matrix is a mixture of $(\mathrm{Bi})$ and eutectic areas. Alloys \#7-\#10 share the same nominal $\mathrm{Ag}$ to $\mathrm{Bi}$ molar ratio equal to $1: 4$. In agreement with the calculated liquidus projection, BiNi was found to be the primary solidification phase for alloy \#7. The microstructure of alloy \#8 (Fig. 5e) resembles microstructure of alloy \#7, in particular $\mathrm{BiNi}$ is embedded in $\mathrm{Bi}_{3} \mathrm{Ni}$, but the amount and size of the (Ag) precipitates and the (Bi) matrix are smaller. Only a few precipitates of (Ni) were found, all adjacent to BiNi. Therefore, the $(\mathrm{Ni})$ is the primary solidification phase for sample \#8, in accordance with the calculated liquidus projection. ${ }^{7}$ In the light matrix, the area occupied by eutectic is relatively small compared to samples of higher Bi content. For alloy \#9, the primary solidification phase is $(\mathrm{Ni})$, whereas the remaining phases are $(\mathrm{Ag}),(\mathrm{Bi}), \mathrm{BiNi}$ and $\mathrm{Bi}_{3} \mathrm{Ni}$. It is the melting of the ternary eutectic which is responsible for the peak recorded at $\sim 535 \mathrm{~K}$ (Fig. $2 \mathrm{~b}$ ), as discussed earlier. The (Ni) was also found to be the primary solidification phase for alloys \#10 (Ag to Bi ratio 1:4), \#11, \#12 (Ag to Bi ratio 1:1), and \#14 (Ag to Bi ratio 4:1).
The microstructure of alloy \#13 (Fig. 7a) is similar to that of alloys \#10 and \#12. There is one exception, however, i.e. sparsely distributed, round precipitates of $30-80 \mu \mathrm{m}$ in diameter. The composition of these precipitates was found to be 97.4 at.\% $\mathrm{Ni}$, with 1.4 at.\% $\mathrm{Ag}$ and 1.2 at.\% Bi. Detailed inspection revealed that their microstructure is not homogenous but they are formed of areas of pure $\mathrm{Ni}$ and a kind of Ni-rich eutectic. The EDS analysis of the area of the remaining part of the sample shows that its composition is almost identical to the nominal composition of alloy \#13. This leads to the conclusion that for this sample two immiscible liquids are observed. Round Ni-rich precipitates are liquid L2, whereas the remaining part of sample represents the microstructure of solidified Ag-rich liquid L1. The small amount of liquid L2, however, suggests that the composition of this alloy is close to the edge of the liquid miscibility gap. The microstructure of alloy \#15 (Fig. 7b) clearly shows two solidified liquids, darker Ni-rich liquid L2 and lighter Ag-rich liquid L1. The composition of liquid L1 (Table II) differs from the nominal composition of alloy \#15 (Table I). This, and a relatively larger size of $\mathrm{L} 2$, indicates that alloy \#15 is deeper in the range of liquid immiscibility than alloy \#13. Both the alloy \#13 and \#15 microstructures of solidified liquid L1 are composed of (Ag), (Bi), (Ni), BiNi, and $\mathrm{Bi}_{3} \mathrm{Ni}$ phases. The results for alloys \#13 and \#15 indicate that the liquid miscibility gap in the $\mathrm{Ag}-\mathrm{Bi}-\mathrm{Ni}$ system is larger 


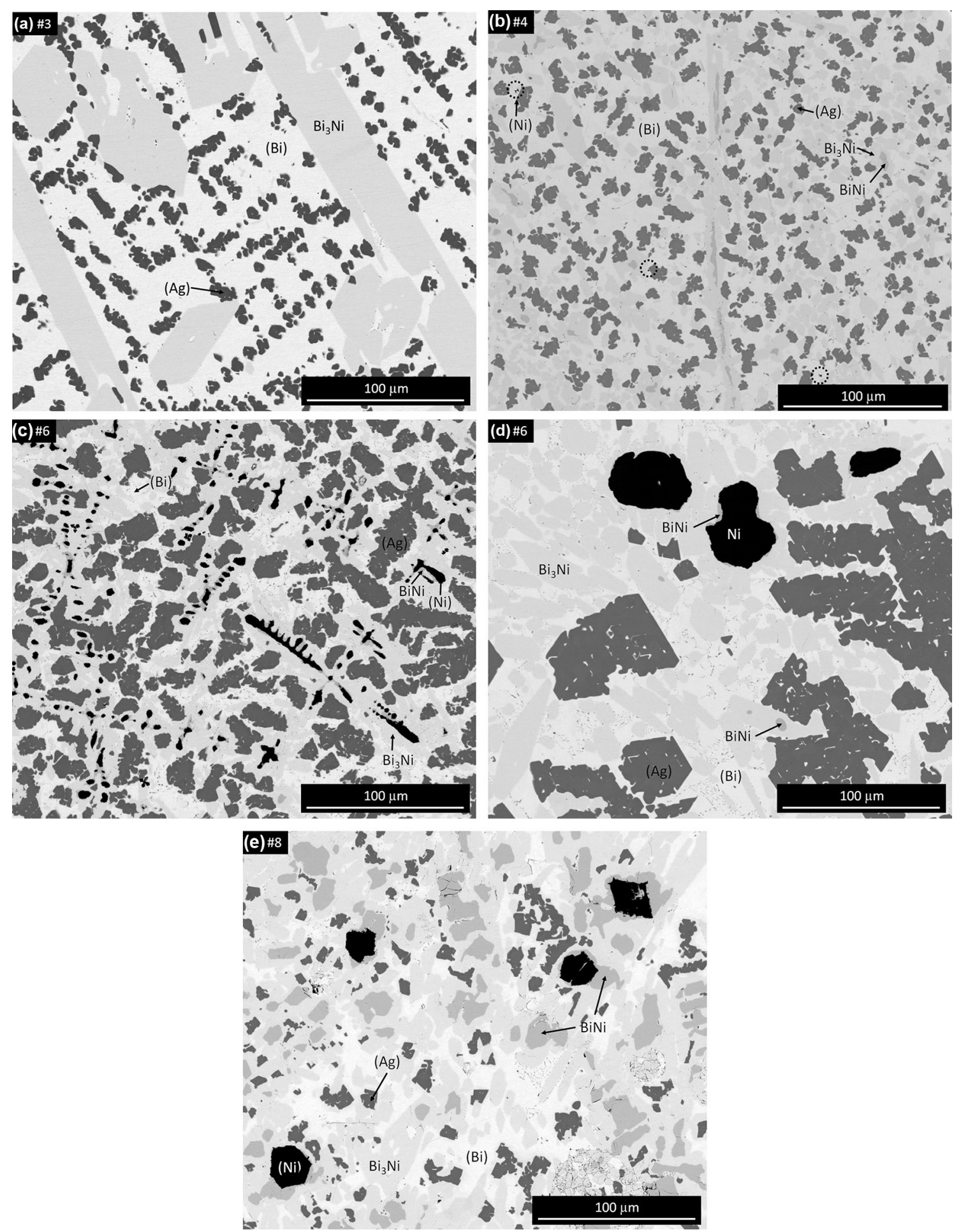

Fig. 5. SEM-BSE micrographs of Ag-Bi-Ni alloys: (a) as-solidified \#3, (b) as-solidified \#4, (c) as-solidified \#6, (d) \#6 after DTA, (e) as-solidified \#8.

than that calculated from the assessed thermodynamic data. ${ }^{7}$

\section{CONCLUSION}

The liquidus projection in the Ag-Bi-Ni ternary system was experimentally studied and compared to the liquidus projection calculated based on thermodynamic assessment in the literature. There are five primary solidification phases in the Ag-Bi-Ni system: $(\mathrm{Ag}),(\mathrm{Bi}), \mathrm{Bi}_{3} \mathrm{Ni}, \mathrm{BiNi}$, and $(\mathrm{Ni})$. The concentration range in which $(\mathrm{Ni})$ is the primary solidification phase was found to be narrower than calculated, while the concentration range in which 


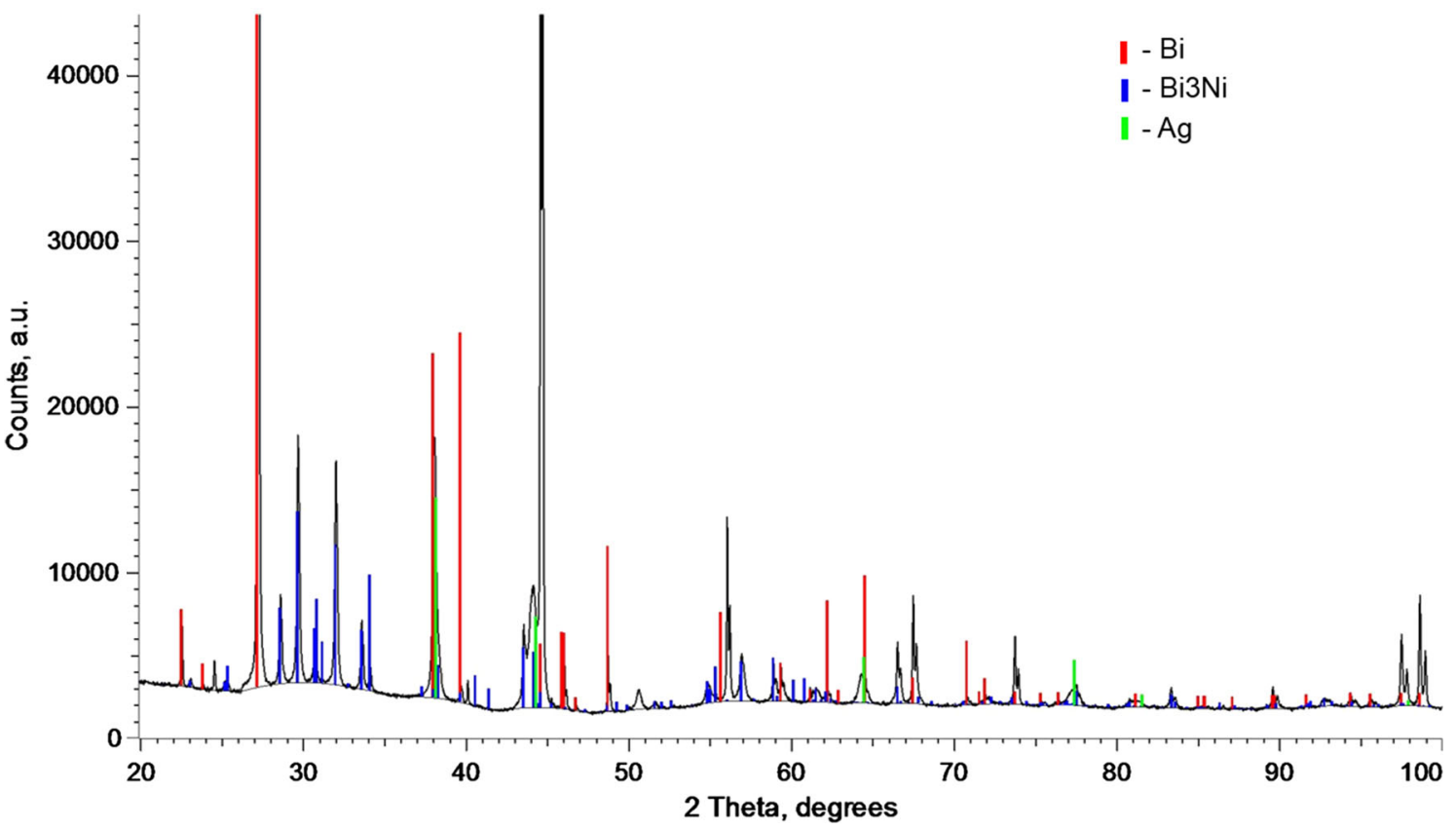

Fig. 6. XRD diffraction of as-solidified alloy \#3 Ag-70Bi-6Ni (at.\%).
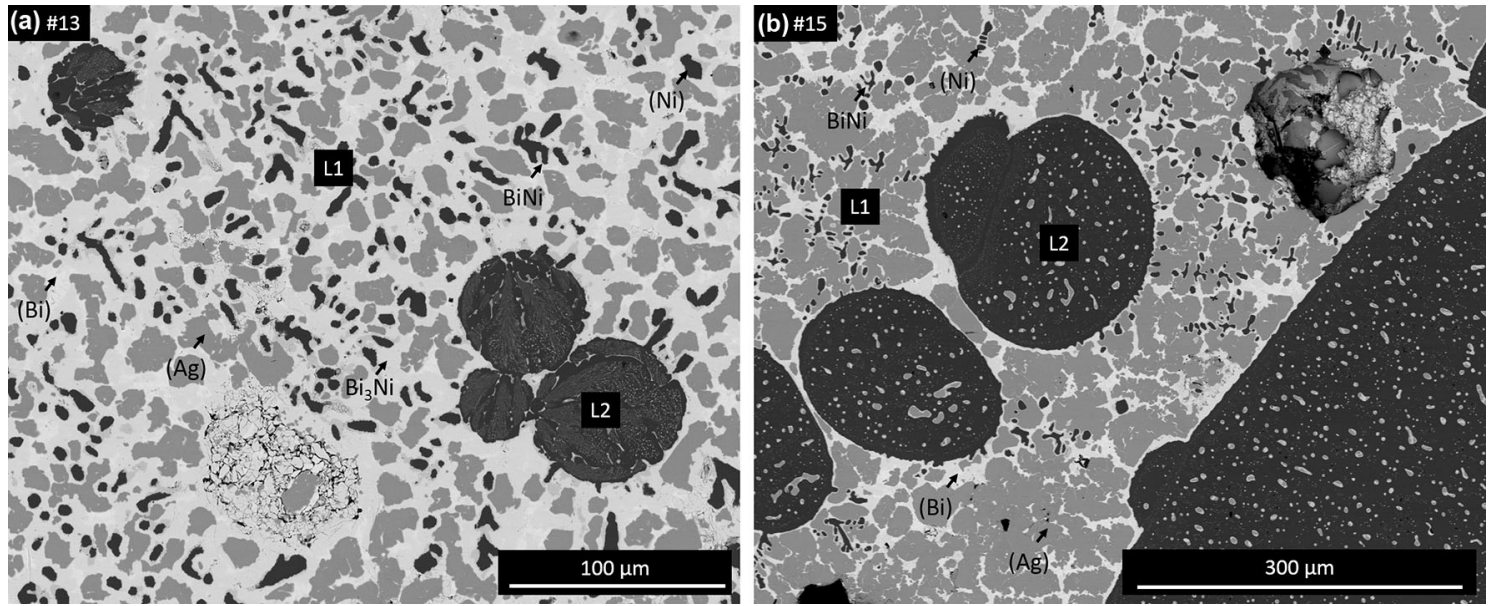

Fig. 7. SEM-BSE micrographs of as-solidified Ag-Bi-Ni alloys: (a) \#13, (b) \#15.

$\mathrm{Bi}_{3} \mathrm{Ni}$ is the primary solidification phase was found to be broader than calculated. It was also found that the liquid miscibility gap is broader than calculated. The calculated transition temperatures were well reproduced by the DTA results, except for a transition at $\sim 535 \mathrm{~K}$ corresponding to a ternary eutectic (liquid $\left.->(\mathrm{Bi})+(\mathrm{Ag})+\mathrm{Bi}_{3} \mathrm{Ni}\right)$. The reason this transition occurred in alloys of lowered $\mathrm{Bi}$ content is that the samples were not subjected to annealing, and therefore their microstructure and phase composition are different from equilibrium.

\section{ACKNOWLEDGEMENT}

This work was financed by the Ministry of Science and Higher Education of Poland (Grant IP2012 035672) in the years 2013-2015.

\section{OPEN ACCESS}

This article is distributed under the terms of the Creative Commons Attribution 4.0 International License (http://creativecommons.org/licenses/by/4.0/), which permits unrestricted use, distribution, and reproduction in any medium, provided you give appropriate credit to the original author(s) and the source, provide a link to the Creative Commons license, and indicate if changes were made.

\section{REFERENCES}

1. J.-M. Song and H.-Y. Chuang, Mater. Trans. 50, 1902 (2009).

2. R. Kolenak and M. Chachula, Solder. Surf. Mt. Technol. 25, 68 (2013).

3. A. Kroupa, A. Dinsdale, A. Watson, J. Vrestal, A. Zemanova, and P. Broz, J. Min. Metall. Sect. B 48, 339 (2012). 
4. K. Doi, H. Ohtani, and M. Hasebe, Mater. Trans. 45, 380 (2004).

5. L. Zabdyr and G. Garzel, CALPHAD 33, 187 (2009).

6. H. Ohtani, S. Ono, K. Doi, and M. Hasebe, Mater. Trans. 45, 614 (2004).

7. F. Gao, C. Wang, X. Liu, Y. Takaku, I. Ohnuma, and K. Ishida, J. Mater. Res. 24, 2644 (2009).

8. U.R. Kattner and W.J. Boettinger, J. Electron. Mater. 23, 603 (1994).

9. G.P. Vassilev, X.J. Liu, and K. Ishida, J. Phase Equilib. 26, 161 (2005).
10. X.J. Liu, F. Gao, C.P. Wang, and K. Ishida, J. Electron. Mater. 37, 210 (2008).

11. J.-S. Chang and S.-W. Chen, J. Electron. Mater. 44, 1134 (2015).

12. A. Sypien and W. Przybylo, Mater. Sci. Technol. 26, 31 (2010).

13. W.J. Boettinger, U.R. Kattner, K.-W. Moon, and J.H. Perepezko, DTA and Heat-Flux DSC Measurements of Alloy Melting and Freezing (NIST Special Publication 960-15: Washington, 2006). 